\title{
"I have a better sense of how interconnected the world is": \\ Student perceptions of learning and global engagement during study abroad
}

\section{Maureen Vandermaas-Peeler}

Elon University

\section{Jennifer Duncan-Bendix Maja Sbahl Biehl \\ DIS, Study Abroad in Scandinavia}

\begin{abstract}
:
The study purpose was to examine U.S. college students' perceptions of their engagement and learning after studying abroad for a semester in Denmark. All students participated in a course focusing on children and adolescents in Scandinavian contexts, a semester-long practicum experience in a Danish educational institution, and two course-embedded travel experiences within and outside of Denmark. Although there were no significant differences in students' pre- and posttest scores on the Global Engagement Survey (Hartman et al., 2015), responses to open-ended prompts provided evidence that students developed knowledge and understanding of themselves and others in multiple cultural and educational contexts. They worked to make meaning of their observations throughout the semester, and established strong relationships with the host community. The practicum and study tour experiences provided ample opportunities for global learning; many students reported that they gained knowledge about diversity and considered issues from the perspectives of local and global communities.
\end{abstract}

\footnotetext{
"Through my field study tours, I had the opportunity to meet with several students who were Middle Eastern refugees. Our discussion allowed me to gain a better understanding of how they were affected by anti-Islamic rhetoric both in Denmark, and from the States. Most importantly, though, I was able to see the students as individuals who were dedicated to performing well in school and were interested in speaking to me."

"I have learned to be silent. Language by speech is not always the correct form of communication. I worked with young children and language can work in a variety of ways. Through pictures, music, art, your hands, body language, etc. It is not easy, but everyone should try to step away from their mother tongue."
} 
In these quotes, U.S. college students offered reflections on their experiences and learning at the conclusion of their semester abroad program in Denmark. Their experiences interacting with people of all ages in diverse contexts provided them with tools to evaluate multiple dimensions of the human experience. Like so many who travel and study abroad, they not only gained insight into the human condition with regard to others' lives, but also reflected critically on their own lives and experiences. Empirical evidence supports the anecdotes so often relayed in sojourners' stories of the powerful impact studying abroad had on their lives; for instance, a large retrospective study of over 6,000 college and university alumni found that study abroad is one of the most important experiences students can have as undergraduates (Paige, Fry, Stallman, Josić \& Jon, 2009). Study abroad has been recognized as a high-impact educational practice that affords significant educational benefits to students (Kuh, 2008; NSSE, 2007).

Increased participation in global educational experiences such as study abroad is an objective of many colleges and universities in the U.S., with the goal of producing graduates prepared to enter the workforce with greater awareness, knowledge, and competencies related to economic, social, and civic global diversity (Dolby, 2007; Engberg, 2013; Hovland, 2014; Norris \& Gillespie, 2009; Tarrant, 2010). According to the Institute of International Education Open Doors Report (2015), one in ten undergraduates in the U.S. studies abroad, with a total of 304,467 participating students in 20132014. This represents an increase of 5\% from the previous report, and aligns with a steady increase in participation rates since the mid-1990's. Although the majority of these students participate in short-term programs with durations of less than eight weeks, 35\% participate in a semester abroad program. Reported benefits of studying abroad range from increased cultural awareness, intercultural sensitivity, and intercultural communication skills; second language gains; a reduction in ethnocentrism in favor of developing ethnorelativity; and interest in further contact with diverse cultures and peoples (Bennett, 1993; Engle \& Engle, 2004; Norris \& Gillespie, 2009; Paige, JacobsCassuto, Yershova \& DeJaeghere, 2003).

Recognizing the importance of integrating global learning into liberal education curricula, the Association of American Colleges and Universities (AAC\&U) partnered with numerous organizations, institutions, and individuals to define global learning, articulate the related values, and suggest student learning outcomes (Hovland, 2014). The definition encompasses the following tenets:

“Through global learning, students should (1) become informed, open-minded, and responsible people who are attentive to diversity across the spectrum of differences, (2) seek to understand how their actions affect both local and global communities, and (3) address the world's most pressing and enduring issues collaboratively and equitably" (Hovland, 2014, p. 1).

Although this definition was meant to be adapted within specific institutional contexts, the emphasis on gaining knowledge about diversity, considering issues within local and global communities, and collaborating to solve problems is at the core of many curricular designs for global learning (Hovland, 2014). Based on an extensive review of the literature, Hartman, Lough, Toms and Reynolds (2015) identified six program-related factors that have the potential to influence highimpact global learning programming, including accommodations (e.g., homestay); extent of language immersion; extent of community engagement; the nature of the course or program; and the extent 
of similarity or difference between visiting students and host communities. Positive outcomes related to the development of intercultural knowledge and competencies are most likely to occur when students are actively engaged with diverse communities (Engberg, 2013; Hovland, 2014). Hovland (2014) suggested that stakeholders should consider how innovative global learning programs use "complexity and cross-discipline backgrounds to the best advantage" (p. 9). However, despite significant national attention to the importance of learning in global contexts, research on specific study abroad pedagogies and practices is relatively limited (Dolby, 2007).

The purpose of the present study was to examine U.S. students' perceptions of their engagement and learning in key facets of the curricular design of one innovative study abroad program in Scandinavia focused on Child Development and Diversity (CDD). Three unique aspects of the program were designed to foster cultural and global engagement, including a required course on child development and diversity in Scandinavian contexts; course-embedded travel within and outside of Denmark to examine course-relevant themes in local and global contexts (known as "study tours" within this program); and a practicum experience in a Danish educational institution.

\section{Educational Experiences Supporting Community Engagement in Global Contexts}

Combining a practicum experience with a study abroad program is one potentially powerful source of learning about international educational contexts. International student teaching opportunities can be transformative and result in significant personal growth, a broader worldview, a deeper understanding of globalization, and increased professional competencies (Moseley, Reeder \& Armstrong, 2008; Pence \& Macgillivray, 2008). In the U.S. and in higher education abroad, teacher preparation programs are increasingly committed to incorporating educational experiences designed to enhance teacher candidates' understanding of and preparation to work with culturally diverse students (Regalla, 2016). Practicum experiences can influence preservice teachers' behaviors, attitudes and knowledge not only about educational processes, but also about working with children from diverse populations (Brodin, 2010; Cohen, Allan, Peters \& Willis, 1976).

Short-term international experiences have been shown to have a positive impact on preservice teachers' personal and professional growth. In one study, students from the U. S. who were preparing to teach in early childhood or elementary education programs participated in a monthlong internship in England, and wrote daily reflections in journals and a final cumulative narrative (Brindley, Quinn \& Morton, 2009). Analyses of the journals, observational notes, and teacher evaluations confirmed that encountering international educational contexts encouraged the preservice teachers to consider multiple perspectives. They reflected on their own professional development in the context of the wider community, and reported learning professional competencies such as managing a classroom. Pence and Macgillivray (2008) also found that a fourweek international practicum in Rome, Italy had a positive influence on preservice teachers from the U.S. Students reported increases in appreciation for diversity, confidence in themselves and their teaching, and a developing respect for language learners in classroom contexts. Students attributed these changes not only to the field experience in the Italian schools, but also to the process of daily reflection and the feedback from faculty (Pence \& Macgillivray, 2008). Extant research supports the conclusion that an international experience can be a critically important "catalyst for accelerated 
professional development" (Brindley et al., 2009, p. 532). However, relatively few such opportunities exist in the field of education, and particularly for an entire semester abroad.

Other disciplines, such as social work and nursing, have a longstanding tradition of placing students in community organizations in local and international contexts. A rapidly growing body of research examines global service-learning (GSL) practices and outcomes (e.g., Gammonley, Rotabi \& Gamble, 2007; Hartman \& Kiely, 2014; Lough, 2009; Niehaus \& Crain, 2013; Whitehead, 2015). Scholars in these fields have developed disciplinary models of practice for community placements for students studying abroad. For example, Fisher and Grettenberger (2015) offered a unique model of community-based participatory study abroad for social work, in which students in short-term courses engage in projects that are responsive to community-identified needs and goals and sensitive to issues of power and privilege in the development of service learning projects in the Global South. According to Gammonley et al. (2007), successful programs "highlight the central importance of human relationships as a vehicle for change ... by promoting reciprocity between incountry hosts and student and faculty participants and with interactions based on mutual respect" (p. 134). Reciprocity between host communities and study abroad programs facilitates critical informational exchanges and deepens intercultural learning (Hartman \& Kiely, 2014).

The present research examined student reflections on their experiences during a semester-long practicum in a child development and/or educational site in the host community during a semester abroad program in Copenhagen, Denmark. Although the design of the practicum is somewhat similar to student teaching experiences in education programs in the U.S., these students were not all preparing to be teachers and in fact, came from a wide variety of majors. The commonality was that they were all enrolled in a core child development and diversity class, and the practicum is a required component of that curriculum. The goal for the practicum experience in all the core courses is to enhance students' understanding of Scandinavian perspectives and practices. The practicum thus had the potential to facilitate students' knowledge of Danish educational systems and enable them to connect theory and practice. As part of this course, the students also visited multiple school systems and child care settings in another region of Denmark, and in another European country, with their professor and fellow classmates. These study tours, as well as additional field visits with other courses, provided an additional lens through which to construct a broader, more global perspective on international educational contexts.

\section{Research Questions}

1. Is there any change in students' global engagement from the beginning to the end of the semester abroad program?

2. What do students know about Danish beliefs about childhood, and how does this compare with views in the United States? Is there any change in the students' belief systems or observations over the course of one semester?

3. How do students reflect on their practicum and study tour experiences at the end of the semester? Specifically, how do they relate these experiences to the course content, their own learning, and their future career paths? What emotions did they experience? Did they experience a sense of belonging during their study abroad program? 


\section{Method}

\section{Program Description}

DIS is a non-profit study abroad institution with locations in Copenhagen and Stockholm, offering semester, academic year, and summer programs taught in English. DIS offers students enrolled in North American universities coursework enriched by faculty who are practitioners in their own fields, as well as field studies, hands-on learning opportunities, and study tours across Europe.

The Child Development and Diversity program (CDD) at DIS is designed for undergraduate students from a wide variety of backgrounds and majors, including child development, education, social policy, human development, sociology, psychology, and many others. Students in the program enroll in one of three core courses: Children in a Multicultural Context, Child Development in Scandinavia, and Children and Youth in Europe. Each of these courses incorporates a short study tour to Western Denmark for three days, as well as a long study tour to Istanbul, Helsinki, and Warsaw, respectively. ${ }^{1}$ These study tours are integrated into the course curriculum as a way for students to gain first-hand experiences of childhood and education from a cross-cultural perspective through visits to child care institutions, schools, community organizations, as well as with local universities and research groups.

In addition to their coursework and travels, students in the CDD program are also enrolled in a mandatory practicum (fieldwork) course component. Based on a survey they complete at the start of each semester, students are placed at a Danish preschool, kindergarten, public school, private or charter school, or after-school program. They complete a minimum of 45-55 hours throughout the semester, attending their site once a week for a total of 10 visits. The practicum course provides the students with the opportunity for critical reflection and direct experience within Danish childcare and educational institutions, and encourages their ability to connect the theories presented in their coursework with their observations and experiences in practice. Faculty at DIS provide on-site supervision, advising, and assignments that strengthen their critical thinking skills, as well as their competencies in working with children in diverse settings and activities.

\section{Participants}

Sixty students enrolled in one of the three core CDD courses during the spring of 2016 were invited to participate in the study. The students attended a wide variety of colleges and universities in the U.S. Although we did not collect information about each institution represented by the participants, DIS has over 200 partner institutions ranging from small private colleges to large public universities. Fifty-two students responded to the pre-test survey, and 36 students completed both the pre- and the post-test surveys. Responses from these 36 participants are the primary focus of the present study. They ranged in age from 19 to 21 years, with the large majority reporting an age of 20 years. Thirty were female, three male and three did not respond to this question. Of these 36 participants, 27 students reported their race/ethnicity as White, two African American, three Asian or Pacific Islander, one other (not specified) and three did not respond. Thirty-one students were born in the United States, two in China, and three did not respond. Nearly all students reported having traveled outside of the U.S. previously.

\footnotetext{
${ }^{1}$ As of the fall of 2016, the study tour to Istanbul, Turkey has been changed to London, England.
} 


\section{Measures}

The measure of global engagement employed in the present research was the Global Engagement Survey (GES) constructed by Hartman et al. (2015). The GES contains 59 closedended questions in three domains including civic engagement, critical thinking, and intercultural competence, all of which relate to global learning as defined by AAC\&U (Hartman et al., 2015; Hovland, 2014). The responses to closed-ended items are on a 5-point scale from 0 (strongly agree) to 4 (strongly disagree). There are also 15 items that assess demographics and program factors such as length and intensity of the placement, as well as 16 open-ended questions that require students to follow up and reflect on some of the closed-ended questions. For example, one item related to intercultural competence is "I can easily resolve misunderstandings with people from other cultures." If the respondent selects agree or strongly agree, this follow-up, open-ended question is prompted: "Can you provide a brief example of a time you satisfactorily resolved a misunderstanding with a person from another culture?" If the respondent answered disagree or strongly disagree, this is the prompt: "Can you briefly explain how you know that you are challenged to easily resolve misunderstandings with people from other cultures?" These responses provide qualitative data enabling a deeper analysis of the self-reported survey responses. The authors are utilizing the GES as a lens through which to gather information on global learning with a diversity of institutions and study abroad as well as domestic programs.

In addition to the standard questions on the GES, we included program-specific questions related to the students' beliefs about childhood, and their practicum and study tour experiences (see Appendix A).

\section{Procedure}

The research was approved by the Institutional Review Board at the university of the first author. In the first week of the semester, during the week of orientation in late January 2016, all CDD students from the three core courses were invited to participate in a survey. They all received an email with a link to the pre-test survey, which they could complete on their own any time in the following week. The first page of the survey included the informed consent; by reviewing and signing, the students agreed to participate. Those who completed the survey were also invited to complete the post-test survey, emailed to them in the last week of the semester in May. The survey was closed approximately two weeks after the email invitation to participate.

\section{Coding and Analyses}

The students' pre- and post-test survey responses were assigned a unique ID and uploaded to Dedoose, a coding software program for qualitative and mixed methods research. The open-ended responses were coded using an iterative process beginning with open coding (Strauss \& Corbin, 1998), in which the first two authors read through all of the pre- and post-test responses to the beliefs about childhood questions, and generated conceptual labels that captured the meaning of the text. We analyzed these codes using constant comparative strategies and placed them into categories. Through joint coding and on-going discussions, the two authors came to $100 \%$ agreement on applying the conceptual labels and the categories to each codable response. We utilized the same process for the remaining responses to open-ended questions, adding new conceptual labels and categorical codes as they emerged in the data. The codes can be found in Appendix B. 


\section{Results}

Analyses of the GES and the program-specific questions are presented in separate sections below. Not all students responded to each open-ended question, and items with very low response frequencies were not included in the following analyses. ID numbers are included with transcript examples as one indicator of the range of responses across individuals.

\section{Global Engagement Survey}

Closed-ended items. The GES (Hartman et al., 2015) is comprised of seven scales in three categories, including Intercultural Competence - Communication; Intercultural Competence - SelfAwareness; Civic Engagement - Efficacy; Civic Engagement - Political Voice; Civic Engagement Conscious Consumption; Civic Engagement - Values; Critical Reflection. The responses (ranging from 0 , strongly agree, to 4, strongly disagree) were reversed so that higher scores indicated increased global engagement. As depicted in Figure 1, there were small increases in the means for each scale from the pre-test to the post-test. However, results of t-tests indicated that there were no statistically significant differences between any of the pre-test and post-test means. Although there were a few individual items on which post-test scores increased significantly, the mean differences on the majority of items did not reach statistical significance and thus only the scale means are reported.

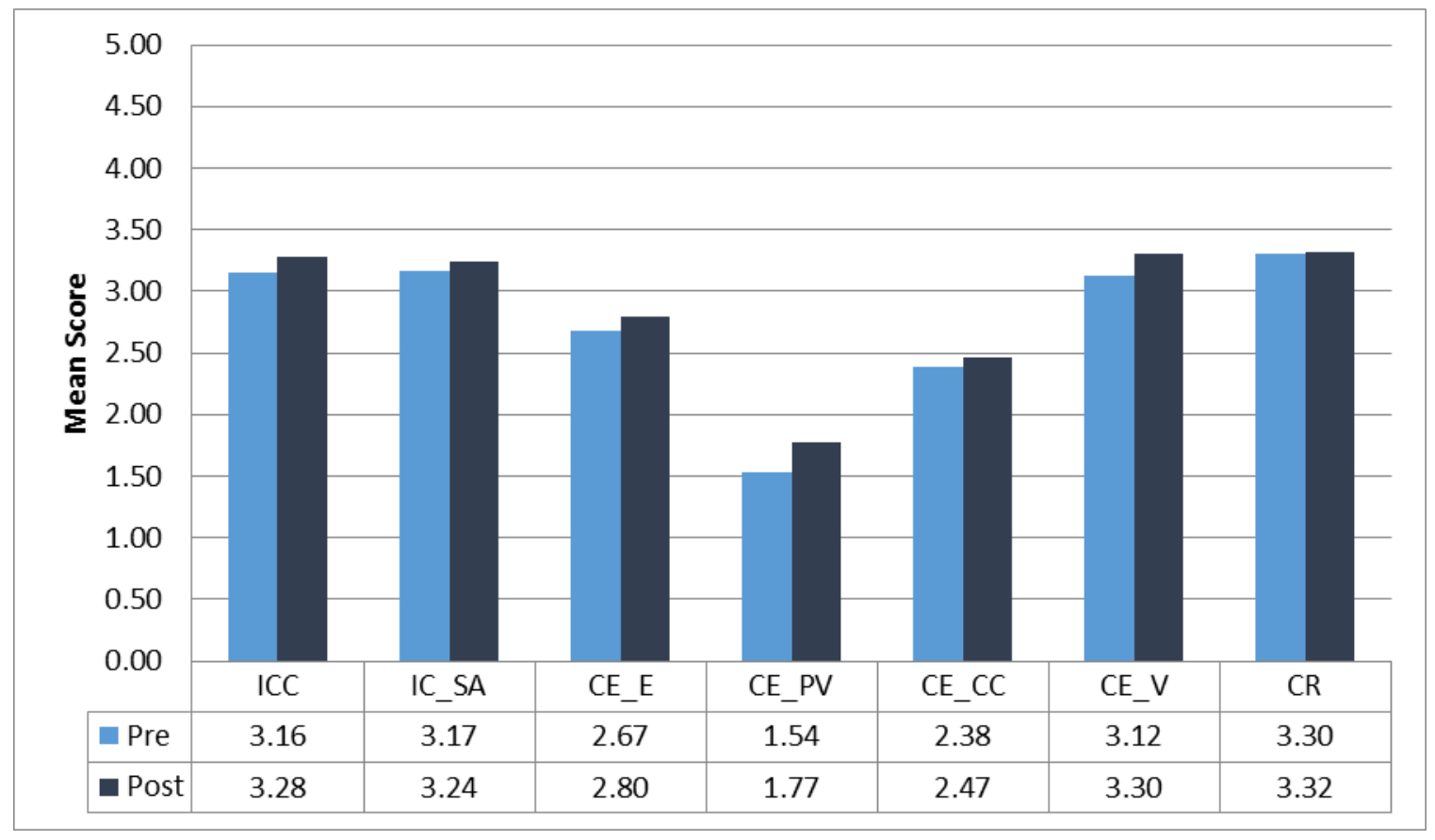

Figure 1. Mean pre- and post-test scores on each scale of the GES

Open-ended questions. Four post-test items on the GES assessed students' experiences during the study abroad program. Analyses and transcript examples are presented for each item below.

In response to the item, At some point, I had to adjust my behaviors in order to behave in a culturally appropriate manner, the majority of respondents agreed or strongly agreed (92\%). The follow-up 
prompt was, Please provide a specific example of what prompted you to adjust your behaviors, and how you did so. The two most frequent codes were Cultural Differences/Diversity and Personal Growth, and the examples provided often related to students' experiences with daily life in Denmark, as in the first quote below with the student commenting on learning the social norms related to public transport. The second two quotes provide examples of ways the students recognized cultural differences and adapted their responses in relation to practicum experiences or their homestay, respectively.

"Noticing the way people act on the public transit prompted me to change the way I act because it was different than in the States. There is less fear of sitting directly next to someone and you always move over when the train gets crowded." ID 34

"I worked with children this semester, and my inclination was to get involved in their play like I did in the US. However, here the adults tend to stay in the background more, so that is what I had to learn to do." ID 27

"Living with my host family, there are different practices that they do that I do not, nothing too extreme just like little moments where I might mess up." ID 24

The quotes above illustrate the critical role of engaging in the community in authentic ways (i.e., completing a semester-long educational practicum and living with a host family) for recognizing and adapting to the cultural context.

In response to the item, How have your experiences in this program influenced your personal sense of your ability to make a difference, Global Engagement and Personal Growth codes were most common. The two transcript examples below highlight the connections between knowledge and practice, with an emphasis on students' developing sense of efficacy.

"My experiences have given me new insights into educational practice and policy, and how it is possible for a school system to practice genuine student-centered education, in which the students (and teachers) are given greater autonomy. Based on my observations, I am eager to influence change in the American education system." ID 11

"I've really felt empowered because of all the knowledge I'm gaining." ID 25

The following responses to the same question exemplify a secondary theme, that the study abroad experiences reinforced extant beliefs or ideologies regarding personal ability to make a difference.

"Working at my practicum site has reinforced my belief in the power that an individual has to make a difference in the lives of others." ID 10

"I think they have reminded me that change happens slowly and through small gestures of kindness and that all help must be culturally appropriate." ID 31

Another item on the GES related to civic engagement was, How, if at all, do you think your experiences in this program have affected your interests in keeping up with political news? The most common code was Cultural Differences/Diversity, and responses reflected students' observations of societal differences in knowledge about local and global politics, as indicated by these quotes:

"The fact that 3rd graders are more up to date with American politics encourages me to be more informed.” ID 53 
"I definitely want to be more informed about the world. I've seen that my host family knows about American politics - they shouldn't know more than I do about my own country!" ID 2

"I feel more inspired to keep up with political news, especially political news outside of the US because I have a sense of place now having traveled outside of the country, and I have been inspired by how well-informed many Europeans seem to be about world politics." ID 20

"I find it much more important now. I think I have a better sense of how interconnected the world is." ID 19

In another item related to civic engagement, students assessed their future advocacy: After this experience, my plans to engage in advocacy have ... Responses were somewhat mixed: 8\% of respondents chose increased significantly, 56\% increased slightly, 33\% stayed about the same, and 3\% decreased slightly. One student commented:

"Seeing how Europe handles parental leave makes me want to advocate for it in the states." ID 4

This quote exemplifies the potential impact of intercultural learning on students' advocacy upon return to their home countries, though further research is needed to close the gap between intentions and actions.

\section{Beliefs about Childhood}

Given that all CDD courses were designed to augment students' knowledge of children and families in a Scandinavian context, two questions on this topic were included in the pre-test and post-test surveys to assess change over time. Although we expected significant increases in reported knowledge at the post-test (with a corresponding increase in number of codes), there were few differences in the total number of coded responses. Interestingly, there were more codes related to Cultural Differences/Diversity at the pre-test, and more codes related to Academic Content at the post-test. The first two quotes below are from pre-test survey responses and the second two are post-test responses.

"Children in Denmark are given much more independence than most children in the US." ID 13

"Danes treat their children with more independence and aren't as worried about them or as overbearing as Americans." ID 16

"Children are treated almost as equals from a young age and are treated very holistically. Also, their social development is considered highly important. Families are much more involved in each other's lives. Throughout the semester I have gained a more practical idea of the way children are treated as opposed to the purely informative idea I had when I first began class.” ID 34

"Denmark is not afraid to let their kids take risks, have their own voice and opinions, and equality. I was surprised when I first came to Denmark because I did not have any prior knowledge about Denmark's treatment of children. After learning about it and experiencing it with my host family I started to adopt it but also remember to be critical of it." ID 6 
As indicated by the contrast between the first two and last two quotes above, students' responses tended to be more general and stereotypical at the pre-test (e.g., "family is very important and they enjoy spending time together"), and more nuanced at post-test (e.g., "more freedom, egalitarianism between children and parents/teachers; my view has changed in that I've seen that not all families are alike and there's a wide range of differences").

At the pre-test students often emphasized that Danes valued family time more and/or were more family-oriented than U.S. families, commented on Danish children's greater freedom and autonomy, and noticed that they spent more time outdoors. At the post-test, students often referenced knowledge gained in class or during the practicum, such as mentioning risk and risky play in the context of visiting or working in a forest kindergarten, or commenting on the Danish views of children as competent beings deserving of equal rights. These were common themes in the course readings and discussions.

\section{Practicum Experiences: Community Engagement and Belonging}

Students were asked to evaluate their cognitive and socio-emotional responses to their practicum experiences in a series of questions at the post-test. When asked if the practicum met their expectations, $76 \%$ agreed or strongly agreed. In regards to experiencing negative emotions relating to their practicum, 61\% agreed or strongly agreed. Analyses of students' explanations yielded a common theme of discomfort related to communication and/or language barriers. Some students also noted that they used these moments as learning opportunities, as exemplified in the second quote.

"I couldn't understand some conversations during my practicum experience and that made me a little uncomfortable not knowing what to do." ID 16

"I was never really negative but maybe uncomfortable in a good way as I knew I was challenging myself.” ID 25

Although their practicum experiences were sometimes uncomfortable, all students also agreed that they experienced positive emotions during the practicum, with $82 \%$ of respondents reporting that they strongly agreed. These responses exemplify this finding:

"Working with the kids brought me joy and excitement." ID 6

"I loved watching the kids try to speak to me in English! I also liked trying to speak to them in Danish." ID 9

"The children and pedagogues seemed genuinely excited to have me there, and the children gave me hugs which was great!” ID 20

"I enjoyed playing with the children and feeling like I was part of the børnehaven family." ID 33

Students' explanations and examples of the positive emotions they experienced centered almost exclusively on the relationships they built with the host community, and particularly getting to know the children through their practicum sites. 
When asked whether they experienced significant learning during their practicum experiences, $70 \%$ strongly agreed and 30\% agreed. The explanation prompt yielded approximately equal codes across these categories: Academic Content, Cultural Differences/Diversity, and Bonding/Relationships. The following responses provide examples across these three categories.

"My conversations with educators at my practicum site were always valuable. From the beginning, I was able to ask my teacher about questions I was thinking about, such as the role of parents in the Danish classroom. These informal conversations continued throughout the semester, and addressed topics ranging from the implementation of individualized instruction to education spending in the local municipality to large-scale policy differences between the Danish, Finnish, and American school systems." ID 11

"Learned about the imperfections of the Danish school system first-hand, and learned to actively think critically of it." ID 30

"I learned a lot about myself as an educator, how to be flexible, about having fun while learning, and sharing stories.” ID 10

Thus, all students agreed that they experienced positive emotions and significant learning, and the majority also acknowledged experiencing negative emotions during their practicum work. Reflecting on their own development also provided the occasion for students to think critically about the educational systems and their roles within them.

Participants were asked to report on one or two of their most significant experiences during practicum. The majority of responses fell into the categories of Academic Content and Positive Emotions. Secondary codes included activities with children; bonding/relationships; communication; and meaning-making, as evidenced in these two responses.

"I really bonded with a one year old just using body language and funny noises. She cried when I would leave even though I never spoke a word she understood. It taught me that most of relationships with young children are built through physical contact and body language." ID 4

"1. During my first visit, my practicum teacher handed her keys over to a few students, so they could take me on a campus tour. This struck me as extremely different from what I would see in the US, and found that it reflected an impressive degree of trust in the students, as well as a cultural difference in terms of how much the school was devoted to providing a rose-colored view of their institution. $\backslash \backslash 2$. I was extremely proud when my 4th-grade students were able to utter full sentences in English. When they began working with me, they would not even look in my eyes and it was a struggle for them to utter single-word responses. I was very pleased with their progress." ID 11

The students' responses provided examples of the ways they derived meaning from working with the children at their practicum site over the course of the semester, and highlighted the challenges they faced with regard to cultural and linguistic differences.

Two questions prompted students to draw connections between their practicum experiences, the core course, and their future career plans. The students used their experiences and knowledge to highlight themes of particular interest or importance to them, as in the quotes below. 
'I will certainly remember the power of teaching to students' interests. Throughout my time at practicum, the students were working on various written English projects. Perhaps because they were motivated by the fact that they were able to pick their own topics, I noticed that the students were nearly always on task. Rather than surfing the Internet, the students were always using their computers to complete their assignments." ID 11

"As a future teacher, I've learned that there are many ways to run a classroom! I must never stop questioning the assumptions of any culture." ID 2

These responses exemplified students' integration of information during the semester as well as looking ahead to their future careers, particularly for those who aspired to become teachers. In an item related to community engagement, the students were asked to assess their sense of belonging during their semester abroad. The majority (85\%) agreed or strongly agreed that they experienced a sense of belonging, and their explanations focused on bonding with classmates, host families, and teachers and children at their practicum sites. These two quotes are indicative of students' connections to various communities during their semester abroad.

"Our core course had a wonderful community and strongly contributed to my sense of belonging. Everyone worked well together and supported each other.” ID 10

"I can tell now that I am leaving that I got very connected to my practicum, my visiting host family, and my Danish rugby team. It is hard to say goodbye." ID 31

The majority of students provided similar examples of belonging to one or more cultural communities. There were only two responses to the question of belonging in which negative emotions were coded:

"I felt astutely aware of being an outsider, both among Danes and Danish society and among other US college students. Although this served as a useful learning opportunity, it was hard to feel out of place and alone all semester." ID 20

"While I felt accepted in my host family and with my friends, it's hard to feel completely like you belong in a country that doesn't speak your language." ID 2

The first quote relays one student's sense of loneliness and isolation during the semester. The second quote reflects the importance of the role of language in belonging to a community, and also conveys a degree of ethnocentrism in the wording (i.e., "a country that doesn't speak your language" instead of "I don't speak Danish") that may have contributed to the student's difficulty in experiencing a sense of belonging.

\section{Study Tour Experiences: Global Engagement and Cross-cultural Comparisons}

The last category of questions related to students' experiences on their study tours. All classes visited Western Denmark for the first travel experience, and traveled either to Turkey, Poland, or Finland for the second study tour. In each travel experience, students visited educational institutions as well as tourist destinations. The study tours met the expectations of $94 \%$ of the respondents, and as with the practicum, many students agreed that they experienced both negative (48\%) and positive emotions $(99 \%)$. Sometimes this related to a difficult visit (e.g., "visiting a ghetto") or to the 
frustrations of trying to make sense of cultural and/or socio-economic differences, as depicted in the quotes below.

"During Istanbul I had a lot of trouble making meaning of what we were seeing. This was really frustrating and confusing for me." ID 2

"It was so hard to see the school with lower-income children, the classes were crowded and obviously underfunded." ID 9

Both comments related to school visits that provoked negative emotions due to the stark contrast between what the students were accustomed to and what they were experiencing. These visits may have provoked discomfort but were also important in terms of experiencing and engaging intercultural differences.

The study tours also afforded opportunities for students to draw cross-cultural comparisons between the U.S., Denmark, and the third country. One student acknowledged the benefits of crosscultural comparisons for generalizing "universal" educational practices such as classroom management, and the second conveyed frustrations with the way the US was portrayed as "ideal" by other students during a discussion of educational practices.

"Throughout the study tour, I was nearly always amazed by what I observed. Even in one case where the school did not come off as very impressive, it was still a valuable learning experience that showed me how common challenges like classroom management are crosscultural with respect to the U.S.” ID 11

“Hard to hear some peoples' (views) of American education. Sometimes I felt like we presented the wrong information to locals, and generalized when we needed to clarify that we were speaking from our own experiences." ID 24

All of the respondents agreed or strongly agreed that they experienced significant learning on the study tours, and many commented that they would use what they were learning in future careers. The quotes below exemplify students' reflections on their own academic and personal growth in relation to experiencing cultural differences and diversity, sometimes connected to a desire for advocacy. The significant experiences they wrote about were most often related to educational visits, but occasionally they referenced other visits or experiences during their study tours.

"Visiting the refugee school and special ed school were incredibly powerful, because they pushed me to challenge my own beliefs." ID 10

"Jumping into a frozen lake after sitting in a sauna in Finland. It gave me an opportunity to challenge myself and do something that scared me.” ID 41

"Seeing that it's possible for other countries to use research to shape their school system has reinvigorated my desire to change things in the States." ID 4

"We never really know, we always have to let ourselves feel uncomfortable and recognize that we are never really experts." ID 24 
As this last response indicates, experiencing humility is one of the ultimate goals of intercultural learning. The qualitative analyses offer supporting evidence for the importance of diverse international educational programming such as practicum and study tour experiences.

\section{Discussion}

We examined U.S. college students' perceptions of their engagement and learning after a semester abroad program in Denmark. The students were enrolled in a child development and diversity course focusing on children and adolescents in Scandinavian contexts, and participated in a semester-long practicum experience in a Danish educational institution, as well as two courseembedded travel experiences within and outside of Denmark. Although there were no significant differences in students' scores on the GES from pre-test to post-test, responses to open-ended prompts provided evidence that students developed knowledge, skills, and understanding of themselves and others in multiple cultural and educational contexts. They worked to make meaning of their observations throughout the semester, and established strong relationships with the host community. The practicum and study tour experiences provided opportunities for global learning; students reported that they gained knowledge about diversity and considered issues from the perspectives of local and global communities (Hovland, 2014). These findings support prior research and theory indicating that positive outcomes related to developing intercultural knowledge and competencies are most likely to occur when students are actively engaged with diverse communities (Engberg, 2013; Hovland, 2014).

Three domains of particular interest for global engagement are civic engagement, critical thinking, and intercultural competence, all of which relate to global learning as defined by AAC\&U (Hartman et al., 2015; Hovland, 2014). In the CDD program, students gain in-depth understanding of educational institutions in multiple cultural contexts throughout their courses, but also by working with one site in or near Copenhagen for an entire semester, and visiting many other schools and programs in Western Denmark and Finland, Poland, or Turkey. Students' reflections indicated that they recognized and appreciated cultural differences, and in some cases adapted their behaviors accordingly. They reflected on observed cultural differences in a variety of contexts, including host family living situations, experiences at their practicum site, and study tour visits. Many examples of adaptive behaviors addressed learning new social norms in Denmark (e.g., "I now look for bikes as well as cars when I cross the street because they are everywhere"), and often reflected a contrast with norms in the United States (e.g., "I noticed that American people are very loud in public compared to Danes, so I made an effort to be quieter and more aware"). Students reported that their experiences in the program encouraged them to reflect on and challenge their beliefs, particularly about educational policies and practices in local and global contexts. These findings support previous research suggesting that international practicum experiences in educational settings can be transformative and result in significant personal growth as well as a deeper understanding of diverse cultures and places (Brindley et al., 2009; Moseley et al., 2008; Pence \& Macgillivray, 2008). The findings from this study also offer new evidence that students from a variety of academic majors and home institutions demonstrated cognitive and socio-emotional benefits from a semesterlong practicum experience in diverse educational institutions. Practicum experiences need not be restricted to preservice teachers, particularly during a semester abroad. Deep engagement with the community can provide opportunities to connect theory and practice, enhance communication and reduce language barriers, as well as foster a sense of belonging. 
With regard to students' knowledge about and understanding of Scandinavian beliefs about childhood, results indicated a decrease in the use of broad generalizations about Danish families and increased connections to academic content and nuanced comparisons over time. At the pre-test administration of the survey, students had only been living in or near Copenhagen for seven to ten days for orientation. By the post-test administration of the survey, they had been living in or near the city for four months and had taken multiple courses introducing them to Danish culture. A comparison of responses to the pre- and post-test questions provided evidence of the importance of connecting knowledge to practice through critical reflection and sustained community engagement. For example, at the post-test several students commented on "the good childhood," a concept introduced in the course readings to capture the Danes' focus on children's competence and rights, which contrasts with a U.S. perspective in many respects (e.g., Wagner, 2006). Many students connected their conceptual knowledge to their observations at the practicum site, utilizing a critical lens. Facilitating community engagement experiences that are meaningfully connected to course content in a study abroad program can be considered a high-quality, high-impact educational practice with the potential for powerful, long-term influences on behavior and attitudes (Kuh, 2008; Paige et al., 2009).

Although engagement in the host community was examined through practicum experiences in this study, the findings highlighted the importance of an additional program-related factor - living in a home stay. This was deemed one of the influential program factors for high-impact global learning by Hartman et al. (2015), and results of this study support this conclusion. Students in the DIS program choose from a wide variety of options for their living situation, including living and learning communities, dorms (some of which also house Danish students), and home stays, among others. It was clear from the responses to the survey that for some students, the home stays were highly significant components of their learning and engagement. No other living arrangement was mentioned frequently. Students often mentioned their host families in the context of developing cultural knowledge about Danes, as well as developing and sustaining emotional connections within the host community. Future research should include questions designed to assess the impact of various living situations on students' engagement with others in the host community.

The study findings are limited by several factors. A majority of students who participate in the DIS program are from relatively privileged backgrounds and attend academically acclaimed colleges and universities in the U.S., and most of our participants identified as White females, limiting generalizability of findings. Additionally, not all CDD students chose to participate in the pre- and post-test surveys, and there may have been inherent biases or differences in abilities between those who did and did not participate. Although many aspects of this program are unique, and few if any directly comparable programs could be found in the literature, future research should include a variety of programs and courses of study to enhance generalizability.

In conclusion, the study findings contribute to a deeper understanding of students' learning and engagement abroad, particularly with regard to the benefits of practicum and course-embedded travel experiences. These salient features of the study abroad program contributed to students' reported community and global engagement, and provided significant opportunities for critical reflections on their own lives as well as others' experiences, as illustrated by this final quote: 
"Every time I meet someone new I am reminded of how my own experiences have shaped how I think and view the world, and I try to understand their perspectives and evaluate my own."

\section{Acknowledgements}

The authors would like to thank the participating students, the faculty members who teach in the CDD program, and administrative staff at DIS for their support. We are grateful to Eric Hartman and his colleagues for developing and sharing the GES, and particularly to Nora Reynolds for administering the survey and organizing the data. Elon University and DIS provided significant support to the first author by affording her the opportunity to teach abroad.

\section{References}

Bennett, J. M. (1993). Toward ethnorelativism: A developmental model of intercultural sensitivity. In R. M. Paige (Ed.), Education for the intercultural experience (pp. 21-71). Yarmouth, ME: Intercultural.

Brindley, R., Quinn, S., \& Morton, M. L. (2009). Consonance and dissonance in a study abroad program as a catalyst for professional development of pre-service teachers. Teaching and Teacher Education, 25(3), 525-532.

Brodin, J. (2010). Education for Global Competencies An EU — Canada Exchange Programme in Higher Education and Training. Journal of Studies in International Education, 14(5), 569-584.

Cohen, A. S., Peters, D. L., \& Willis, S. L. (1976). The effects of early childhood education student teaching on program preference, beliefs, and behaviors. The Journal of Educational Research, 70(1), $15-20$.

Dolby, N. (2007). Reflections on Nation: American undergraduates and education abroad. Journal of Studies in International Education, 11 (2), 141-156.

Engberg, M. (2013). The influence of study away experiences on global perspective-taking. Journal of College Student Development, 54 (5), 466-480.

Engle, L., \& Engle, J. (2004). Assessing language acquisition and intercultural sensitivity development in relation to study abroad program design. Frontiers: The Interdisciplinary Journal of Study Abroad, 10, 253-276.

Fisher, C. M. \& Grettenberger, S. E. (2015). Community-based participatory study abroad A proposed model for social work education. Journal of Social Work Education, 51 (3), 566-582.

Gammonley, D., Rotabi, K. S., \& Gamble, D. N. (2007). Enhancing global understanding with study abroad: Ethically grounded approaches to international learning. Journal of Teaching in Social Work, 27(3-4), 115-135.

Hartman, E., \& Kiely, R. (2014). Pushing boundaries: Introduction to the global service-learning special section. Michigan Journal of Community Service Learning, 21 (1), 55-63.

Hartman, E., Lough, B. J., Toms, C. \& Reynolds, N. (2015). Assessing intercultural capacities, civic engagement, and critical thinking: The Global Engagement Survey. In J. Friedman, V.

Haverkate, B. Oomen, E. Park, \& M. Sklad (Eds.). Going glocal in higher education: The theory, teaching and measurement of global citizenship (pp. 127-145) Middelburg, NL: University

College Roosevelt.

Hovland, K. (2014). Global learning: Defining, designing, demonstrating. Washington, D.C.: Association of American Colleges and Universities. Retrieved from http://www.aacu.org/globallearning

Institute of International Education Open Doors Report. (2015). Retrieved from http://www.iie.org/Research-and-Publications/Open-Doors\#.Vys0lyN95-U

Kuh, G.D. (2008) High-impact educational practices: What they are, who has access to them, and why they matter. Washington, D.C.: Association of American Colleges and Universities.

Lough, B. (2009). Principles of effective practice in international social work field placements. Journal of Social Work Education, 45 (3), 467-480. 
Moseley, C., Reeder, S, \& Armstrong, N. (2008). "I don't eat White." The transformational nature of student teaching abroad. Curriculum and Teaching Dialogue, 10 (1 and 2), 55-71.

Niehaus, E. \& Crain, L. K. (2013). Act local or global? Comparing student experience in domestic and international service-learning programs. Michigan Journal of Community Service Learning, 20 (1), 31-40.

Norris, E. M., \& Gillespie, J. (2009). How study abroad shapes global careers evidence from the United States. Journal of Studies in International Education, 13(3), 382-397.

National Survey of Student Engagement (NSSE) (2007). NSSE 2007 annual report. Retrieved from

http://nsse.iub.edu/NSSE_2007_Annual_Report/docs/withhold/NSSE_2007_Annual_Report.pdf

Paige, R. M., Fry, G. W., Stallman, E. M., Josić, J., \& Jon, J. E. (2009). Study abroad for global engagement: the long-term impact of mobility experiences. Intercultural Education, 20(sup1), S29S44.

Paige, R. M., Jacobs-Cassuto, M., Yershova, Y. A., \& DeJaeghere, J. (2003). Assessing intercultural sensitivity: An empirical analysis of the Intercultural Development Inventory. International Journal of Intercultural Relations, 27, 467-486.

Pence, H.M., \& Macgillivray, I.K. (2008). The impact of an international field experience on preservice teachers. Teaching and Teacher Education, 24, 14-25.

Regalla, M. (2016). Getting out of their comfort zone: Examining teacher candidates' reactions to servicelearning abroad. Multicultural Perspectives, 18(2), 65-72.

Strauss, A., \& Corbin, J. (1998). Basics of qualitative research: Techniques and procedures for developing grounded theory. Thousand Oaks, CA: Sage Publications, Inc.

Tarrant, M. A. (2010). A conceptual framework for exploring the role of studies abroad in nurturing global citizenship. Journal of Studies in International Education, 14 (5), 433-451.

Wagner, J. T. (2006). An outsider's perspective. Childhoods and early education in the Nordic countries. In J. Einarsdottir \& J.T. Wagner (Eds). Nordic childhoods and early education (pp. 289-306). Greenwich, CT: Information Age Publishing.

Whithead, D. M. (2015). Global service-learning: Addressing the big challenges. Diversity and Democracy. Washington, D.C.: Association of American Colleges and Universities.

\section{Appendix A}

Pre- and Post-Test Questions Added to the GES

Pre- and Post-Test

Please select your core course in CDD or "other" if you are in a different program.

Child Development in Scandinavia

Children and Youth in Europe

Children in a Multicultural Context

Other (please specify)

Please select the type of practicum site you worked in, if you are a CDD student:

Vuggestue $(0-3$ years old; Nursery/Day Care)

Børnehave (3 - 6 years old; Preschool/Forest Preschool)

Børnehave klasse (5-6 years old; Kindergarten)

Folkeskole (5- 17 years old; K-9 grades; Public School, primary and secondary)

SFO and Klub (After school programs, 5-12 years old and $12-17$ years old)

Other (please specify) 
Please select the housing option that applies to your living situation during your semester with DIS in Copenhagen:

Homestay with a host family

Living and learning community (LLC)

Kollegium

Residential community

Folkehøjskole

Rented room or Independent housing

1. Briefly describe your knowledge regarding the Danish view of children and families. PostTest addition: Has your understanding changed over the semester, and if so, please explain briefly.

2. What similarities and differences do you expect (post-test modification: did you observe or learn about) with regards to beliefs and treatment of children in Denmark as compared with the United States?

Post-Test addition: Was this what you expected to find, or were you surprised by any of the comparisons?

\section{Post-test Only Questions}

Please choose a rating from 1 to 5 for each question, with 1 being "strongly disagree" and 5 "strongly agree" and explain your rating briefly.

Please answer the following questions about your practicum experiences:

1. My practicum experience met my expectations (explain briefly).

2. I experienced negative emotions (e.g., confusion, discomfort) during my practicum (explain briefly).

3. I experienced positive emotions (e.g., excitement) during my practicum (explain briefly).

4. I experienced significant learning during my practicum (explain briefly).

5. Looking back on it, what were one or two of the most significant experiences you had during the practicum? Describe the experience(s) briefly and why these moments stood out to you.

6. Can you relate any of your practicum experiences to the course materials in your core course? If so, please explain briefly.

7. How might you integrate this knowledge/experience gained from the program into your future studies or career?

Please answer the following questions about your study tour experiences:

8. The study tours met my expectations (explain briefly).

9. I experienced negative emotions (e.g., confusion, discomfort) during the study tours (explain briefly).

10. I experienced positive emotions (e.g., excitement) during the study tours (explain briefly).

11. I experienced significant learning during my study tours (explain briefly).

12. Looking back on it, what were one or two of the most significant experiences you had on one of your study tours? Describe where you were (country, context) and why these moments stood out to you. 
13. How might you integrate this knowledge/experience gained from the program into your future studies or career?

14. I experienced a sense of belonging during my semester abroad (explain briefly).

\section{Appendix B}

$\underline{\text { Codes and sub-codes }}$

Academic Content

Core or elective courses mentioned

Specific theories or concepts

Applying knowledge across contexts

Cultural Differences/Diversity

Specific aspects of Danish culture (e.g., freedom for children; importance of spending time outdoors)

Specific aspects of U.S. culture (e.g., emphasis on achievement in school)

Global and Community Engagement

Host community engagement

Civic engagement

Advocacy

Intercultural competence

Communication

Language Differences/Barriers

Nonverbal communication

Bonding/Relationships

Activities with children

Getting to know the children and staff

Bonding with classmates

Living Situation

Host family

Other living arrangement

Personal Growth

Meaning-making

Positive Emotions

Negative Emotions 